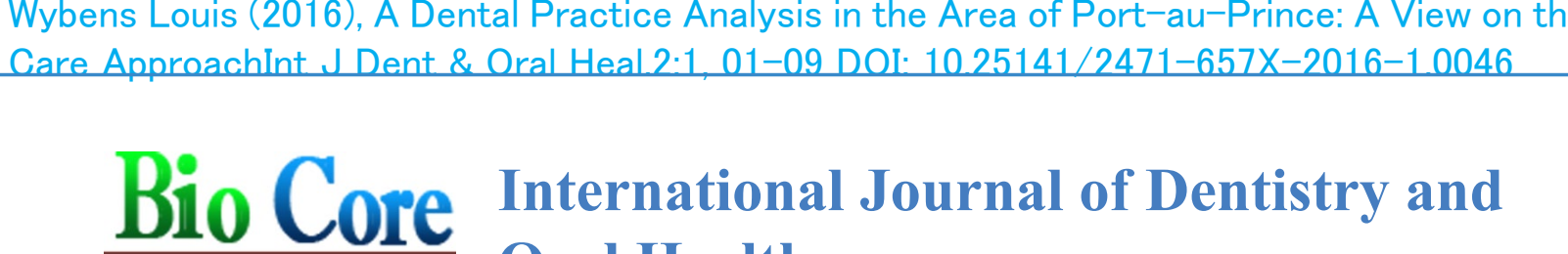 \\ Exploring scientific community Oral Health
}

ISSN 2471-657X

Base Report

DDOD ABPOSS

\section{A Dental Practice Analysis in the Area of Port-au-Prince: A View on the Integrated Periodontal Care Approach}

Wybens Louis*

DDS, MSc, MPH - Research Coordinator, State Dental School of Haiti, Deputy Head of Prosthodontics

Department, FMC, Haiti, USA

Corresponding Author: Wybens Louis, Research Coordinator, State Dental School of Haiti, Deputy, Head of Prosthodontics Department, FMC, Haiti, USA

Citation: Wybens Louis (2015), A Dental Practice Analysis in the Area of Port-au-Prince: A View on the Integrated Periodontal Care Approach. Int J Dent \& Oral Heal. 2:1, 1-9.

DOI: $10.25141 / 2471-657 X-2016-1.0046$

Copyright: (C2015 Wybens Louis. This is an open-access article distributed under the terms of the Creative Commons Attribution License, which permits unrestricted use, distribution, and reproduction in any medium, provided the original author and source are credited

Received: November 15, 2015; Accepted: December 06, 2015; Published: June 23, 2016

\section{ABSTRACT:}

The aim of this study was to identify and evaluate some structural aspects of the dental care supply and demand, its mechanism and then characterizes the periodontal preventive activity in the region of Port-au-Prince. We had conducted between January and February 2012 an epidemiological survey, using a questionnaire that we had administered tothe dentists operating in Port-au-Prince.

Our analysis of 230 questionnaires revealed a dental practice that is almost private and which is largely carried out by men. Our results also indicated that the dentist population in this region happens to be quite young. Most of the demands resulting from dental consultation are related topain or bleedings. The preventive periodontal act was the most practiced.Althoughmany interventions has been performed in periodontal surgery.

Practitioners in the two categories think that a reference should be addressed in severe cases and even if the number of years of experience affect their position towards the built-in support.A fact is that the two groups are agreed that this type of approach is the ideal.

Key words: Oral Practice, Dentists, Integrated Approach and Periodontics

\section{Introduction}

For the WHO (WHO, 2003), the oral health is contributory to the overall health since it leads to an improved quality oflife (1). This decisive capital of wellbeing, unfortunately, can be affected by many risk factors, which exert a strong influence in the onset of many diseases both oral and systemic (2). The associative effect between some oral diseases, particularly periodontal disease and systemic diseases has been proved highly significant $(3,4,5,6,7,8)$.
Periodontal disease is considered as an inflammatory disease that is accompanied of bone destruction and tooth mobility, in severe forms. This untreated situation will result in the loss of the tooth structure (9), which will restrict intensifies the quality of life of individuals $(10,11)$.

Many recent researcheshave shown that periodontitis is a global scourge in terms of complications and by the cost they have generated $(12,13,14)$. This situation is worse in developing countries (14), both, 
due to the negative effect of a lack of resources on the system or the lack of a strategic approach to reducing the systemic effect mediators of periodontal disease on the general health (15). Hence, some authors propose the establishment of appropriate management strategies both preventive and curative, called the integrated participative approach which includes both, the health professionals and the community $(16,14)$.

Thus, the effectiveness of these approaches requires proper assessment of the sector, in terms of supply and demand for care, the establishment of an adequate monitoring system and political will.

In Haiti, the data on such approaches are almost non-existent and there are no epidemiological studies describing the periodontal activity in the country. Therefore, the knowledge of the habits and the attitudes of the population in terms of the nature of the demand; the knowledge of the operational, strategicapproach of the professionals in terms of periodontal activity is required to understand their mechanism of action compared to the new directions $(17,18)$.

This study, therefore gives the purpose to identify and assess the structural aspect of the dental care supply and demand, and to characterize the mechanism of preventive periodontal activity in order to improve access to better knowledge of the built-in support of the oral health of the population.

\section{HYPOTHESIS AND METHOD}

\section{1-Research Hypothesis}

a. The dentists aged between 30 and 45 years account for more than half of the professionals surveyed

b. Eighty percent $(80 \%)$ of these dentists are "general practitioners"

c. The majority of the dentist's respondents believe that constraints around demand are economic

d. The majority of cases diagnosed are not referred to specialty

e. Sixty percent $(60 \%)$ of periodontal diseases are supported only partially

2-Material: Study framework, population and sampling

The study concerned the dentists who have their activity in the region of Port-au-Prince and its surroundings. Many of the respondents are located in the center of Port-au-Prince in particular at the Max Cadet Foundation and at other nearby clinics, others come from municipalities and communities located on the outskirts of the metropolitan area.

This is a descriptive, cross-sectional survey, which was conducted during the year 2012 (between January and February 2012).

Our population was chosen on the basis of their clinical activities, the clinical approach in connection with the prevention of periodontal disorder and the consequences of periodontal disease and their point of view of the new caring approaches.

For our sample, the following inclusion criteria were considered:

-Being a graduate in dentistry and exercising the profession at the time of the survey in Port-auPrince, there was no distinction of sex or age.

-Have established his business in the Port-au-Prince area and agreed to participate in the survey.

We therefore excluded all those who have no business in the capital.

According to some studies, there is no formal estimate of dentist practicing in the area of Port-au-Prince available until now. However, these studies assume that almost $64 \%$ of those who left the faculty are practicing in the metropolitan area $(19,20)$.

Thus, we used this information to power through the formula below, estimate the size of our sample:

Let $\mathrm{n}$ the size of the sample where $\mathrm{n}=\mathrm{Z2}$.pq / $\mathrm{d} 2$ with:

$-Z=1.96$ standard errorsof a type I first species of risk $\alpha$ of $5 \%$;

- $D$ is the degree of error with $95 \%$ confidence interval (desired precision);

- $P$ is the estimated proportion of dentist and practicing in the capital $(19,20)$;

$-Q$ is the complement of the proportion $(q=1-p)$

The initial sample size was then estimated at about 354 for an $\alpha$ risk of $5 \%$

\section{3-Data Collection}

Data collection was performed using a selfadministered questionnaire, anonymous, written before by the research sponsors and whose pre-test was 
conducted with a group of ten [10] internal students of the dental school at the University autonomous Port-au-Prince (UNAP).

This questionnaire included the following components:

- Personal characteristics (age and sex);

- The mode and the type of exercise (Private Practice, Practice Community or Mixed)

- The number of years of experience;

- Information on care demand, built-in support and monitoring mechanisms and their views on obstacles to periodontal care demand.

In total two hundred eighty (280) questionnaires were distributed, two hundred and fifty (250) were recovered, representing a participation rate of over $80 \%$. However, two hundred and thirty eight (238) have been encoded, due to poor filling of the other.

\section{4-Studied Variables}

The variables included in the study were

- Demographic variables:

- Age

- Sex

- For professional practice:

- The exercise class, private office - underCommunity or mixed practice

- The number of years of experience

- For the toward behavior about the demand and periodontal approach

- Demand characteristics

- Reference

Characteristics of the study sample

\section{The types of acts}

Our data were coded and encoded then analyzed with the software Epi-info 7.1.4. The usual statistics were used for the description of the sample (mean, standard deviation, proportion).

The Pearson Chi-square test was used to compare proportions, when conditions were not met Fisher test was calculated instead.

The Odds ratio with their confidence interval of $95 \%$ (95\% CI) were estimated to measure the strength of association between characteristics such as age, sex, number of years of experience, periodontal built-in support and the perception of the dentist on barriers related to access, etc.

Dentists were recruited on a voluntary basis following a presentation of the study elements. It should also be noted that the survey questionnaire contained no identifying information likely to prejudice the right of the respondents. The anonymity of respondents was also respected in the collection of data, and no link has been established between individuals in the analysis thereof.

\section{RESULTS}

The size of the sample used in the analysis was subject to variations which was caused first by the willingness to participate of the dentists and then by the quality of the returned questionnaires. Therefore, the predetermined size performs with the standard size formula has not been reached. Indeed, only 250 questionnaires were returned, among which 12 were not consistent for encoding and analysis. This situation could be responsible for some influence on some of our results.

Table 1 summarizes the socio-demographic characteristics of the sample.

Table 1. Characteristics of the study sample

\begin{tabular}{|c|c|c|c|c|c|}
\hline Socio-demographic variables & $t_{n}=238$ & $\%$ & Mean & \pm & $\mathrm{SD} *$ \\
\hline Age (year) & & & 33 & \pm & 6,25 \\
\hline \multicolumn{6}{|l|}{ Sex } \\
\hline Men & & 75,49 & & & \\
\hline Women & & 24,51 & & & \\
\hline
\end{tabular}


The average age of dentists who participated in the study was 33 years. The men were in the majority, more than $70 \%$.

Figure:1 shows a distribution of dentists depending on their practicetype. As shown in this figure (Fig.1) almost half (47\%) of dentists in the metropolitan area of Port-au-Prince works in private practice. While nearly one in six (1/6) develops a mixed activity (i.e., two or all three modes simultaneously).

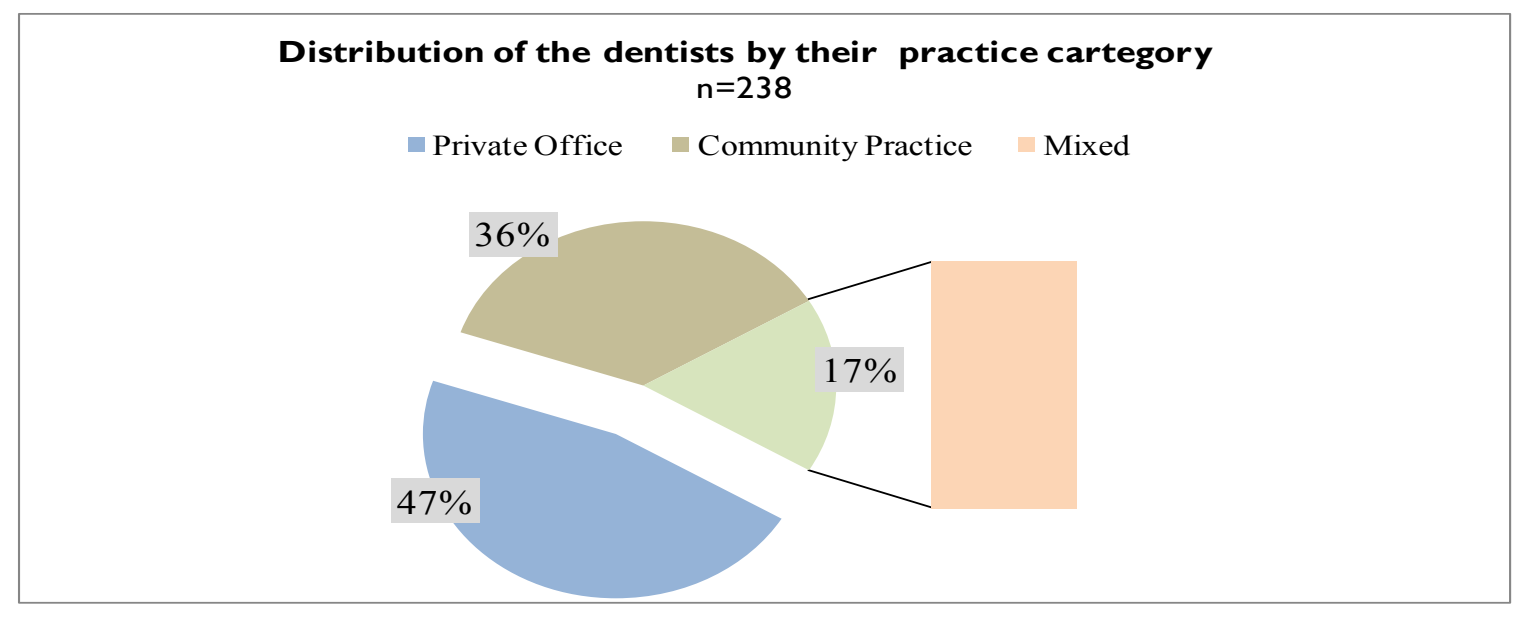

Fig-1. Distribution of dentists per practice category

Table-2. Relationship between the perceptions of dentists on constraints related to access and their age

\begin{tabular}{|l|l|l|l|}
\hline Age (year) & Economic Constraint (\%) & OR (IC95\%) & P-value \\
\hline & & & 0,67 \\
\hline$\leq 35(n=183)$ & 39,74 & & \\
\hline$>35(n=54)$ & 34,78 & $1,23(0.47 ; 3,26)$ & \\
\hline
\end{tabular}

Table 2.shows that the opinion of the dentists on the economic factor as an obstacle to the access and the dental care demand differs in terms of the proportion between the two subgroups of ages. However, this difference was not statistically significant $(p=0.67)$.

Table-3. Distribution of the dentists based on the number of years of practice experiences

\begin{tabular}{|l|c|}
\hline $\begin{array}{l}\text { Number of yearofpractice experiences } \\
(n=230)\end{array}$ & $(\%)$ \\
\hline$<5$ years & 56,86 \\
\hline$<10$ years & 32,35 \\
\hline$<10$ years & 10,79 \\
\hline
\end{tabular}

Regarding the distribution of the dentists taking into account the number of years of experience, we can see that more than half of our cohort had less than 5 years of experience (Table 3 ). 


Care ApproachInt J Dent \& Oral Heal2:1,01-09 DOI: $1025141 / 2471-657 X-2016-10046$
Table-4. Distribution of the patients demand based on the inducements of the initial consultation
\begin{tabular}{|l|c|}
\hline \multicolumn{1}{|c|}{ Consultation inducements } & $\mathrm{n}=230$ \\
\hline \multicolumn{1}{|c|}{} & $(\%)$ \\
\hline Routine & 11,76 \\
\hline Dental Trauma & 21,57 \\
\hline Sensitivity & 17,65 \\
\hline Abscess & 3,92 \\
\hline Toothache & 9,80 \\
\hline Other Emergency & 27,45 \\
\hline
\end{tabular}

The results in Table 4 show that the demands in oral care are generally triggered by three main factors. There is more demand caused by dental pain and bleeding as observed in this cohort

Table-5. Distribution of the dentists based on their type of practice

\begin{tabular}{|l|c|}
\hline \multicolumn{2}{|c|}{ Type of Practice } \\
\hline \multicolumn{1}{|c|}{$\mathrm{n}(230)$} & $(\%)$ \\
\hline General Practitioner & 95,10 \\
\hline Specialist & 4,90 \\
\hline
\end{tabular}

Table-5. shows that more than $90 \%$ of dentists in the metropolitan area have recognized that they are running their practice as a general practitioner.

\begin{tabular}{|l|c|}
\hline \multicolumn{1}{|c|}{ Type of periodontal activities } & $(\%)$ \\
\hline Bone graft \& filling & 23,29 \\
\hline Gingival graft & 8,22 \\
\hline Gingivectomy/Gingivoplasty & 31,51 \\
\hline Scaling-Surfacing & 36,99 \\
\hline
\end{tabular}

From Table 6 , over $60 \%$ of interventions in terms of periodontal activities are surgical. While the preventive activities or nonsurgical occupy more than one third (36.99\%) of clinical activity observed.

Table-7. Relationship between the type of practices and the opinion of the dentists about the reference to specialty for severe periodontal diseases

\begin{tabular}{|l|l|l|l|}
\hline Type of practice & Reference to specialty (\%) & OR (IC95\%) & $*$ P-value \\
\hline & & & 0,39 \\
\hline General Practitioner $(n=218)$ & 93,8 & & \\
\hline Specialist $\quad(n=12)$ & 84,7 & $2,9(0.3 ; 15,7)$ & \\
\hline
\end{tabular}

*Fisher Test

In Table 7, we observed that the degree of expression of the opinion of dentists towards reference in cases of severe periodontal diseases is twice as large among general practitioners. Nevertheless, the difference in terms of proportion of responses is not statistically significant $(p=0.39)$.

Table -8. Relationship between the number of years of experience and the position of dentists towards the integrated participative approach plan

\begin{tabular}{|l|l|l|l|}
\hline Number of years & Systematic Approach built-in (\%) & OR (IC95\%) & $*$ P-value \\
\hline & & & 0,0001 \\
\hline More than 10 years $(n=67)$ & 66 & & \\
\hline Less than 10 years $(n=163)$ & 89,5 & $4,45(2,18 ; 9,22)$ & \\
\hline
\end{tabular}


From Table 8, less they have year experiences more they agreed to towards implementation of an integrated plan of systematic management of severe periodontal diseases.

A relationship that has a high degree of dependence and whose the position difference between the two groups is statistically significant.

\section{DISCUSSION}

Characteristic of the profession seen in its sociodemographic context

In the region of Port-au-Prince and its surroundings, mainly in the metropolitan area, the practical mode of oral medicine develops in private practice. As a fact, nearly half ( $47 \%$ ) of participants runs a private practice. This proportion is about the double $(83 \%)$ in Quebec (21) with a much stronger tendency, almost $98 \%$ for all of Canada. This situation is not different in Europe, where the dentists almost 8 out of 10 develop their private office practice (22). In the US, the proportion is very similar to that of Canada or approximately $91.7 \%$ (23).

The average age was 33 years old in our study. This average is proceeding somewhat lower than that observed in Quebec and Canada, where the average age in 2012 was 45 years old(21), very close to that of France (47) at 2006 (24). While slightly higher, the US average was 50 years old between 2009 and 2010 (25). This fact, in reality, can be explained by the configuration of the age in countries such as the USA and Canada related the migration phenomenon, which mean, many foreign dentists have integrated the North American market after practicing a few years in their country. This puts us in the presence of the population with an elderly propensity.

Although the trend shows some growth in the proportion of women entering the dental profession (26), men in our study are still to be in the majority. It is noticed that in most countries the picture is the same. In our study the female to male ratio is 1 to 4 . Then it is approximately 2 to 5 in Canada and even more in Quebec (21). In Europe, the ratio follows the Canadian dynamic, a proportion of women representing of our report is somewhat similar to that of the USA where women in the profession in term of proportion approximately $42 \%$ (22). The results correspond to $22.2 \%$ (23). However the proportion of women exercising the profession in France is slightly above that of our study, $34.7 \%$ (24).

The proportion of dentists who have a training leading to the exercise of a specialty is low (less than $5 \%$ ). This effect towards a general practice may be related to the economics conditions of the population or of the investment in terms of time to devote to training and money that requires for a specialization.

Reason for the demand

The demand for dental care is especially triggered by pain as noted by our study. This represents more than a quarter of the conditions leading to a consultation with the dentist. It follows the reality described by some authors $(27 ; 28 ; 29)$, who studied the demand for consultation with a dentist in Europe and Canada.

The survey also reveals that the demand in terms of access to oral health care is influenced by economic conditions. According to the study data (Table 2), economic constraints are the factors most retain by dentists to explain the inaccessibility of the population to oral health care. The study of Msefer Laroussi - S (30) in Quebec highlighted the same conclusions by analyzing the demand for oral care. For this author, and according to the findings revealed in the opinion of dentists in our study, the disadvantaged population show very little attention to oral care because of its estimating expensive costs. This reflects well the concept of socio-economic and cultural disparity in the accessibility of oral care as described by Poul Erik Petersen (14).

\section{The built-in periodontal care support}

According to our results, most dentists relate that they perform surgical management of cases of periodontitis. However, the preventive interventions occupy an important place in their practice (Table 6). The results show that the interventions in periodontal treatments, such as gingival graft and frenectomy were very few realized. However, our results differ very little of what had found Ghiabi Edmond and Deborah Matthews C (31).

Although aware that their treatment costs are a limiting factor for the evolution of the practice, especially the periodontal treatment, taking into account the low economic level of the population and the costs in terms of material resources and 
facilities, a high proportion of dentists all practice confused considers it necessary to address severe cases to specialty (Table 7).As to the systematic built-in support that is part of an integrated plan for periodontal treatment, opinion differs depending on the number of years of experience. That is a determinant factor, if we considering the significant gap between the assessments of the two groups (Table 8). This may be due to the weight of experience and expertise developed over the years, as noted by the study Ghiabi and Matthews (31).

CONCLUSION: Limits of the study and appreciation

Our work presents some limitations. The questionnaire was self-administered, so, the results of our survey are based on the validity of the data collected by such a questionnaire. This type of survey, however, a good tool to get information about a large number of individuals and, therefore, is used in several research.Our survey was conducted among dentists with activity in Port-au-Prince. Although most of them work in another town, our results should not be extrapolated to the whole nationwide.Since, initially the context may be different given the large attraction of the metropolitan area and secondarily a few questionnaires came from a concentric area like the Max Cadet Foundation or the Dental School of the University Autonome of Port -at -Prince. An important element was that the number of unreturned questionnaires and not taken into account, was insignificant, which is important in term of statistical power.

Moreover, one could have looked at the relation between the type of exercise and the number of periodontal acts, but for strategic reasons we had omitted this analysis.

Despite these limitations, the study allowed us to appreciate a part of the image of dentistry in Portau-Prince and in other parts of the world, particularly in Quebec. It also allowed us to draw a portrait of the demand and the levels of perception of dentists about the constraints related to accessibility then at the integration for a systematic preventive approach for manage periodontal disease.

The information gathered may not only serve to supply the development in the future, a mapping of professionals and their activities but also as a guide for a deeper analysis for an implementation of the accompanying program and support to disadvantaged people requiring a built-in periodontal care support. Thus, further studies on the accompanying mechanism for specialty dentists and the social structure' $s$ ability to deliver quality basic care and cost are therefore necessary.Finally, this study will help to highlight and support the proposal of the PAHO made through the research of Estupiñán-Day Saskia (20) who analysed both the interest and the need to integrate the oral health into the national health plan.

\section{REFERENCE}

1. The World Oral Health Report 2003: Continuous improvement of oral health in the 21 st century - the approach of the WHO Global Oral Health Program, Genève (Suisse)

2. SHEIHAM $A$ and al, 2000: 《The common risk factor approach; a rational basis for promoting oral health 》Community Dent Oral Epidemiol, 28(6): 399-406

3. OKORO C A and al, 2005: 《 Tooth loss and heart disease: finding from the Behavioral Risk Factor Surveillance System 》. Am J Prev Med; 29: 50-6

4. KHADER Y S and al, 2004: «Periodontal diseases and the risk of coronary heart and cerebrovascular diseases: meta-analysis 》. J Periodontal; 75: 1046-1053

5. KINANE D, and BOUCHARD P, 2008: «Periodontal diseases and health: Consensus Report of the Sixth European Workshop on Periodontology 》. J Clin Periodontol 35:333-337

6. GOMES-FIHLO I S, PASSOS J S, SEIXAS DA CRUZ S, 2010. Respiratory disease and the role of oral bacteria. J Oral Micro; 2:5811

7. LALLA E and PAPAPANOU P N, 2011. Diabetes mellitus and periodontitis: a tale of two common interrelated diseases. Nat Rev Endocrinol; 7: 738748

8. LOCKHART P B, BOLGER A F, PAPAPANOU $P N$, and al, 2012. Periodontal disease and atherosclerotic vascular disease: does the evidence support an independent association?Circulation; 125: 2520-2544.

9. ANAES, Rapport 2000 : Parodontopathies : 
Diagnostic et Traitements

10. BELLON P. et coll., 2003 : 《Epidémiologies des maladies parodontales 》. Université de Rennes 1 ; Centre recherche en Parodontologie, dossier No129

11. PETERSEN Poul Erick, 2007 : 《Pour la Promotion de la Santé Bucco-dentaire et la Prévention Intégrée des Affections》. Santé Solidarité Développement, Information Dentaire No 10 , cahier 2, pp 4-5

12. BELLON P. et coll., 2003 : 《Epidémiologies des maladies parodontales 》. Université de Rennes 1 ; Centre recherche en Parodontologie, dossier No129

13. SIXOU M, 2003 : 《Epidémiologie des maladies parodontales. In les thérapeutiques parodontales et implantaires, Eds. Quintessence international, pp 85-98

14. PETERSEN Poul Erik and Hiroshi Ogawa, 2005: 《Strengthening the Prevention of Periodontal Disease: The WHO Approach》 J Periodontal, December 2005 Vol. 76, No. 12, pp 1-7

15. COULIBALY N T, et coll., 2001. 《Prévalence des parodontites en Afrique noire : influence des facteurs socioéconomiques et des habitudes culturelles 》. Odonto-Stomatologie. Trop., Vol $24 \mathrm{~N}^{\circ} \quad 94: 37-41$

16. BARMES D E, 1999: 《A global view of oral diseases today and tomorrow 》. Comm Dent Oral Epidemiol, vol. $27: 2-7$

17. RASOAMANANJARA J A et coll. 2008. 《maladies chroniques et attitude des chirurgiens dentistes à Madagascar》. Med Trop; 68: 519-522

18. ARCHANA J S and SRINATH S, 2009. 《 Relationship of periodontal Status and Dental Caries Status with Oral Health Knowledge, Attitude and Behavior among Professionnal Students in India》. Int J Oral Sci, 1(4): 196-206

19. ESTUPINAN-DAY Saskia and al: Global Health through Oral health of Haiti. Compendium of Continuing Education in Dentistry, vol. 32, Issue 2, Mars 2011

20. ESTUPIÑÁN-DAY Saskia, LAFONTANT Christina and ACUÑA Maria Cecilia, 2011.Integrating Oral
Health into Haiti National Health Plan.From disaster relief to sustainable developpement. Rev Panam Salud Publica, 30(5): 484-9.

21. LUSSIER JP et Benigeri : 《L'organisation de la pratique de médecine dentaire au Québec. Journal de I' ordre des dentistes du Québec. Volume 44, Septembre 2007.

22. Le chirurgien dentiste en France : Exercice et cabinet. Revue no 1650-1651, p 14, Février 2015.

23. ADA Survey Report, 2011. Distribution of dentist in the United States by region and by State in 2009.

24. BRILLANT Anne et al. Les évolutions démographiques des professionnels de sante. Edition santé et protection sociale, 2006, p 556.

25. VALACHOVIC W. Richard, 2009. Current demographics and future trends of the dental workforce. Institute of medicine.

26. MCKAY C. Julia et Carlos R. Quiñonez, 2012. La féminisation de la dentisterie : Répercussions sur la profession. Can Dent Assoc 2012;78:c1_f.

27. MENDOMO EYA' ANE E.M et al, 2001. La pauvreté et I'ignorance : les causes des consultations tardives en odontostomatologie au $\mathrm{CHU}$ de Yaoundé. Odonto. Stomatol. Trop., Vol $24 \mathrm{~N}^{\circ}$ 94: 11-14, 2001.

28. PRATS E et al, 2005. Consultations dentaires au $\mathrm{CHU}$ de Toulouse : place des soins conservateurs. Santé Publique 2005/2, Vol. 17, pp 255-264.

29. RICHARD Anne, 2007. Santé gingivale : résultats d'un état des lieux sur la prise en charge des maladies parodontales en France. Enquête nationale de santé dentaire, Congres de la société française de parodontologie et d' implantologie orale.

30. MSEFER-LAROUSSI Souad, 2007. Analyse du système de couverture des services dentaires au Québec. Thèse doctorale, Université de Montréal - Faculté de Médecine, DASUM-GRIS, pp1-287.

31. EDMOND Ghiabi, Debora C. Matthews, 2012.Profil des dentistes généralistes de la Nouvelle-Écosse en ce qui a trait à la pratique parodontale et aux demandes de consultation dans cette spécialité.J Can Dent Assoc 2012;78:c55_f. 


\section{Acknowledgments:}

Our thanks go to the Max Cadet Foundation and its partners, the State dental school of Haiti, The Dental medical school of the University Autonome of Port-au-Prince, Dr Houslène Rene Louis, Dr. Jean Mirlintz, Dr Odile J. Casimir, Dr. Benedict Larose, Dr. Arnoux Lefranc, Dr. Eudor Dorlyn, Dr. Francis Davidson, Dr. Joubert Tingue, Dr. Jean René David, Dr Jeanel Saint Louis, Cassandra Jules and all our colleagues that I could not mention their names here and helped either by filling or distributing our questionnaires. 